\title{
PENGARUH PEMANFAATAN MEDIA AUDIO VISUAL DALAM PEMBELAJARAN SENI TARI TERHADAP HASIL BELAJAR PADA SISWA KELAS XI SMA DARUSSALAM MEDAN
}

\author{
DIAN RIDHAYANI \\ Prodi Pendidikan Tari
}

\begin{abstract}
This study discusses the Influence Use of Audio Visual Media in Learning Dance Of Learning Outcomes In High School Student Class XI Darussalam aims to describe the field and know the effect of the use of audio-visual media to the learning outcomes of students in dancing Ranup Lampuan in SMA Darussalam Medan. To discuss the purpose of the study above, use the theories related to the topic of this research is the theory of learning, learning theory, dance, theory of learning outcomes and audio-visual media. Time used in this study is for 2 (two) months, namely in July 2016 to August 2016. The study site is a Private School High School Darussalam Medan is located on the street. Darussalam No. 26 $A B C$, Petisah Medan, Medan, North Sumatra. The population in this study were high school Darussalam Medan, while samples were students of class XI IPA SMA Darussalam Medan. Analysis of the data in this study using quantitative descriptive, namely data collection techniques by observation, library research, assessment questionnaires, and documentation. The results based on the data collected can be seen that the ability of the students in learning the dance Ranup Lampuan class XI SMA Darussalam Medan before and after using audio-visual media obtained by the average value of 65.10 and 76.95 . From these data it can be seen an increase in the value of before use and after use audio-visual media. Learning Dance Ranup Lampuan using audio-visual media positive and significant impact on learning outcomes of students of class XI SMA Darussalam Medan.
\end{abstract}

Keywords : Audio-visual 
PENDAHULUAN

Pendidikan merupakan salah satu kebutuhan pokok dalam kehidupan manusia yang berfikir bagaimana menjalani kehidupan dunia ini dalam rangka mempertahankan hidup dan penghidupan manusia yang mengemban tugas dari Sang Kholiq untuk beribadah.Manusia sebagai makhluk yang diberikan kelebihan oleh Allah SWT dengan suatu bentuk akal pada diri manusia yang tidak dimiliki makhluk Allah yang lain dalam kehidupannya, bahwa untuk mengolah akal pikirnya diperlukan suatu pola pendidikan melalui suatu proses pembelajaran.

$$
\text { Kosasih Djahiri (1980 : 3) }
$$

mengatakan bahwa "Pendidikan merupakan upaya yang terorganisir, berencana dan berlangsung kontinyu (terus menerus sepanjang hayat) kearah membina manusia/anak didik menjadi insan paripurna, dewasa dan berbudaya".

Keberhasilan proses pembelajaran merupakan hal utama yang didambakan dalam pelaksanaan pendidikan di sekolah. Dalam proses pembelajaran komponen utama adalah guru dan peserta didik. Agar proses pembelajaran berhasil, guru harus membimbing peserta didik semikian rupa sehingga mereka dapat mengembangkan pengetahuannya sesuai dengan struktur pengetahuan bidang yang dipelajarinya. Untuk mencapai keberhasilan tersebut disamping guru harus memahami sepenuhnya materi yang diajarkan, guru dituntut mengetahui secara tepat posisi pengetahuan peserta didik pada awal (sebelumnya) mengikuti pelajaran tersebut.

Salah satu usaha untuk mengatasi keadaan demikian adalah penggunaan media dalam proses belajar mengajar. Karena fungsi media dalam kegiatan tersebut disamping sebagai penyaji stimulus informasi, sikap dan lain-lain, juga untuk meningkatkan keberhasilan dalam menerima informasi. (Usnita,2013:18) mengatakan bahwa "Media juga berfungsi untuk mengatur langkah-langkah kemajuan serta untuk memberikan umpan balik pada proses belajar mengajar". karena dengan menggunakan media pembelajaran tidak terkesan membosankan bagi siswa, karena siswa tidak hanya mendengarkan ceramah dari guru tetapi dengan menggunakan media pembelajaran siswa akan lebih tertarik dengan pelajaran yang disampaikan dan siswa akan terdorong motivasi belajarnya serta memperjelas dan mempermudah konsep yang abstrak dan mempertinggi daya serap atau retensi belajar.

Media audio visual merupakan alat peraga yang bersifat dapat didengar dan dapat dilihat sehingga dapat membantu siswa dalam proses pembelajaran yang berfungsi memperjelas atau mempermudah 
dalam memahami gerak yang sedang dipelajari. Media audio visual juga merupakan sarana dan prasarana untuk menunjang terlaksananya kegiatan pembelajaran serta menunjangpendidikan dan pelatihan tentunya perlu mendapat perhatian sendiri.

$$
\text { Hasil belajar merupakan }
$$
perwujudan kemampuan akibat perubahan prilaku yang dilakukan oleh usaha pendidikan. Kemampuan tersebut menyangkut domain kognitif, afektif, dan psikomotorik. Hasil belajar tampak sebagai terjadinya perubahan tingkah laku pada diri siswa yang dapat diamati dan diukur dalam bentuk perubahan pengetahuan sikap dan keterampilan.Perubahan tersebut dapat diartikan terjadinya peningkatan dan pengembangan yang lebih baik dibanding dengan yang sebelunya.Hasil belajar ini dapat dilakukan dengan mengamati terjadinya perubahan tingkah laku tersebut setelah dilakukan penilaian.

Pengalaman pembelajaran seperti di atas memberikan pemikiran baru bagaimana merancang sebuah pembelajaran dapat menumbuhkan motivasi siswa dalam belajar sehingga dapat meningkatkan hasil belajar. Muncul suatu gagasan untuk berkolaborasi mencari solusi masalah diatas untuk menemukan cara bagaimana mengembangkan kemampuan yang dimiliki oleh siswa. Bagaimana memanfaatkan kemampuan tersebut agar mereka terus termotivasi dalam belajar dan dapat meningkatkan hasil belajar mereka.

Pendidikan seni budaya dan keterampilan yang diberikan pada sekolah karena memiliki peranan yang sangat penting dalam kebutuhan perkembangan anak dalam mencapai tingkat kecerdasan yang optimal.Kecerdasan anak tidak hanya dapat dilihat dari seberapa banyak pengetahuan yang dimiliki namun juga bagaimana siswa dapat mengekspresikan melalui seni dan keterampilan. Seni budaya dan keterampilan adalah salah satu mata pelajaran yang memfasilitasi anak untuk mengembangkan kecerdasan kinestetik. Dalam standar pendidikan nasional SBK dibagi menjadi tiga macam yaitu seni tari, seni rupa, dan seni musik.

Pencapaian tujuan pembelajaran dan meningkatkan hasil belajar merupakan tugas utama seorang pendidik. Salah satunya dengan menggunakan media audiovisual sebagai stategi pembelajaran yang aktif, kreatif, efektif, dan menyenangkan adalah suatu strategi pembelajaran yang diharapkan. Seni tari merupakan salah satu cabang dari seni budaya. Tari merupakan ekspresi jiwa manusia dapat diwujudkan dalam bentuk simbol yang mengandung arti yang beraneka ragam.Tari salah satu bagian dari budaya, digunakan sebagai sarana untuk 
mengekspresikan keindahan dari dalam jiwa seorang manusia.

Media yang digunakan sebagai rangsangan keterampilan menari siswa yaitu dengan menggunakan media audio visual. (Usnita,2013:25) mengatakan "Keuntungan yang diperoleh dari penggunaan media audio visual yaitu gambar dapat di slow motion, sehingga teknik gerak dapat dipahami siswa secara mendetail, gambar dapat diulang berkalikali sehingga pembelajaran dipergunakan seefesien mungkin”. Maka Rangsangan audio visual yang dihadirkan harus dapat membuat suasana pembelajaran menarik. Selain itu, peran guru biasanya mendemonstrasikan gerak, dapat menggunakananya sebagai media bantu dalam membimbing siswa secara menyeluruh, materi pembelajaran yang dibuat kedalam VCD bisa dipelajari dirumah sehingga siswa dapat terus berlatih tanpa mengandalkan pertemuan di kelas saja.

Kekurangan dalam penggunaan media pembelajaran berupa audio visual yaitu terbatasnya ruangan yang dapat dipergunakan untuk kebutuhan tersebut yaitu harus ruangan khusus dan lengkap dengan multi media itu sendiri.Selain itu dengan menggunakan infocus, penerangan ruangan tidak bisa terlalu terang, hal ini agar siswa dapat melihat kejelasan visualisasi yang terdapat pada layar.
Dengan pertimbangan yang telah dikemukakan diatas, maka penulis melakukan penelitian dengan judul “ Pengaruh Pemanfaatan Media Audio Visual Dalam Pembelajaran Seni Tari Terhadap Hasil Belajar Pada Siswa Kelas XI SMA Darussalam Medan“.

\section{Tujuan Penelitian}

1. Mendeskripsikan proses pembelajaran seni tari melalui media audio visual pada siswa kelas XI SMADarussalam Medan.

2. Mendeskripsikan pengaruh pemanfaatan media audio visual terhadap hasil belajar siswa dalam menari tarian Ranup Lampuan di SMA Darussalam Medan.

\section{Landasan Teori}

Landasan teoritis adalah pedoman berfikir dalam melaksanakan suatu penelitian.Kerangka konseptual merupakan rangkaian pengertian tentang objek agar diperoleh pembahasan yang jelas dan tepat. teori-teori yang berhubungan dengan topik penelitian ini yaitu teori pembelajaran, teori pembelajaran seni tari, teori hasil belajar dan media audio visual .

\section{Kerangka Konseptual}

Kerangka Konseptual merupakan salah satu bagian dari penelitian yang paling penting. Konsep adalah gejala paling penting dalam suatu penelitian yang digunakan sebagai alat menggambarkan 
fenomena,dengan adanya penjabaran masalah teoritisnya.

\section{Lokasi dan Waktu Penelitian}

Lokasi penelitian dilakukan di SMA Darussalam Medan yang terletak dijalan Darussaam No. 26 ABC, Medan Petisah, Medan, Sumatera Utara. Penelitian dilakukan selama 2 (dua) bulan, yaitu bulan Juli 2016 sampai Agustus 2016.

\section{Populasi dan Sampel}

Populasi

Populasi dalam penelitian ini adalah sekolah SMA Darussalam Medan.

\section{Sampel}

Sampel dalam penelitian adalah para siswa kelas XI IPA SMA Darussalam Medan.

\section{Instrumen Penelitian dan Teknik}

\section{Pengumpulan Data}

Instrumen yang digunakan untuk menjaring data dalam penelitian ini adalah quesioner dengan penyebaran angket kepada siswa. Teknik pengumpulan data yang dilakukan adalah sebagai berikut:

1. Observasi Lapangan

2. Dokumentasi

3. Kajian Pustaka

\section{Teknik Analisis Data}

Analisis data yang digunakan dalam penelitian ini adalah teknik analisis kuantitatif yang terkumpul melalui observasi, penilaian dan dokumentasi. Semua data yang diperoleh di lapangan selanjutnya dianalisis secermat mungkin untuk dirumuskan dan dijadikan bahan tulisan sebagai hasil dari penelitian yang dilakukan. Langkah-langkah pengolahan teknik analisa data yang diperoleh dilakukan dengan perincian sebagai berikut:

1. Uji Normalitas Data

2. Uji Homogenitas

3. Uji T-Test

\section{ISI}

1. Kemampuan Siswa Kelas XI IPA SMA Darussalam Medan Mengenai Pembelajaran Tari Ranup Lampuan sebelum menggunakan Media Audio visual

Sebelum Menganalisis data, sebaiknya terlebih dahulu mengetahui jumlah sampel dalam penelitian ini yaitu berjumlah 46 orang. Dan sebelum dilakukan perlakuan pada siswa kelas XI IPA SMA Darussalam Medan terlebih dahulu diberikan pretest. Dalam hal ini, data terbesar 90 dan data terkecil 50. dapat diketahui bahwa pengaruh pengajaran menganalisis pembelajaran tari termasuk kategori baik 14 siswa atau 30,43\%, kategori cukup sebanyak 30 siswa atau $65,21 \%$, kategori kurang 1 siswa atau $2,18 \%$, kategori sangat kurang 0 siswa atau $0 \%$. Identifikasi hasil tes tersebut dalam kategori normal dan wajar. Dikatakan normal dan wajar karena kategori yang 
paling banyak dalam tabel $\mathrm{X}$ adalah cukup.

\section{Hasil belajar siswa setelah menggunakan media audio visual kelas XI IPA SMA Darussalam Medan}

Dengan demikian diperoleh hasil kemampuan siswa mengenai pembelajaran tari tergolong dalam kategori cukup dengan nilai rata-rata (mean) sebesar $=65,1$, standart deviasi $=8,06$, Standart error $=$ 1,2 dengan nilai terendah 50 dan nilai tertinggi 90. Dengan demikian hasil kemampuan siswa mengenai pembelajarantari berada pada kategori cukup.

maka dapat diketahui bahwa kemampuan menganalisis kemampuan menganalisis pembelajaran tari berbasis multimedia termasuk kategori sangat baik sebanyak 7 siswa atau 15,2\%, kategori baik 39 siswa atau $84,8 \%$, kategori cukup 0 atau $0 \%$,kategori kurang 0 siswa atau $0 \%$, kategori sangat kurang 0 siswa atau $0 \%$. Identifikasi hasil tes tersebut dalam kategori normal dan wajar.Dikatakan normal dan wajar karena kategori yang paling banyak dalam tabel $\mathrm{X}$ adalah baik.

\section{Pengujian Hipotesis}

Hipotesis yang akan diuji dalam penelitian ini adalah $\mathrm{H}_{\mathrm{a}}=$ ada pengaruh yang signifikan antara pembelajaran tari
Ranup Lampuan dengan menggunakan media audio visual pada siswa kelas XI IPA SMA Darussalam Medan.sebelum diuji berdasarkan uji persyaratan analisis data, hipotesis tersebut diubah menjadi hipotesis nihil $\mathrm{H}_{0}=$ tidak ada pengaruh yang signifikan antara pembelajaran tari Ranup Lampuan dengan menggunakan media audio visual pada siswa kelas XI IPA SMA Darussalam Medan. Sebelum dilakukan pengujian hipotesis, terlebih dahulu dilakukan uji persyaratan analisis data yaitu : Uji Normalitas, uji homogenitas dan pengujian hipotesis.

\section{Pembahasan Penelitian}

Terlihat dari temuan penelitian bahwa hasil pembelajaran tari sebelum menggunakan media audio visual tergolong dalam kategori kurang dengan nilai rata (mean) yaitu 65,10, yang mendapat nilai sangat baik 1 siswa atau $2,18 \%$, kategori baik sebanyak 14 siswa atau 30,43\%, kategori cukup 30 siswa atau $65,21 \%$, kategori kurang 1 siswa atau $2,18 \%$. Ini dikarenakan siswa sedikit aktif berpartisipasi dalam proses pembelajaran, siswa terlihat sedikit jenuh dalam belajar karena yang berperan secara keseluruhan yaitu guru. Disini guru menjelaskan materi pembelajaran dan siswa hanya menyimak dan mencernanya. Oleh karena itu siswa kurang kreatif untuk mengembangkan ide- 
idenya dalam mengembangkan gerak-gerak tari.

Kemudian untuk hasil pembelajaran tari yang menggunakan media audio visual tergolong dalam kategori baik dengan nilai rata-rata (mean) yaitu 76,95. Yang mendapat nilai sangat baik 7 siswa atau $15,2 \%$, baik sebanyak 39 siswa atau $84,8 \%$. Ini dikarenakan cara yang digunakan lebih memusatkan kegiatan pada siswa sehingga siswa bisa mengikuti pelajaran dengan mengembangan ide-ide nya.

Setelah ditemukan hasil diatas maka dapat dicari $\mathrm{F}_{\text {tabel, }} \mathrm{F}_{\text {tabel }}$ dapat diketahui dengan rumus $\frac{\text { Varians Terbesar }}{\text { Varians Terkecil }}=\frac{76,95}{65,10}=\quad 1,18$, setelah itu didapatkan $\mathrm{t}_{0 .} \mathrm{t}_{0 \text {. }}$ pada penelitian ini $t_{0}$ adalah 6,69. Karena $t_{0}$ yang diperoleh lebih besar dari $t_{\text {tabel }}$ yaitu 6,6>4,13, maka hipotesis nihil $\left(\mathrm{H}_{0}\right)$ ditolak dan hipotesis alternative $\left(\mathrm{H}_{\mathrm{a}}\right)$ diterima. Hal ini membuktikan bahwa pengaruh pembelajaran tari Ranup Lampuan menggunakan media audio visual berpengaruh positif terhadap hasil belajar siswa.

\section{PENUTUP}

\section{Kesimpulan}

Dari hasil penelitian dan pembahasan, maka dapat diambil beberapa kesimpulan sebagai berikut:

1. Kemampuan siswa dalam pembelajaran tari Ranup Lampuan dikelas XI IPA SMA Darussalam Medan sebelum menggunakan media audio visual diperoleh nilai rata-rata 65,10 berada pada kategori cukup.

2. Kemampuan siswa dalam pembelajaran tari Ranup Lampuan dikelas XI IPA SMA Darussalam Medan sebelum menggunakan media audio visual diperoleh nilai rata-rata 76,95 berada pada kategori baik.

3. Pembelajaran tari Ranup Lampuan dengan menggunakan media audio visual berpengaruh positif dan signifikan teerhadap hasil belajar siswa kelas XI IPA SMA Darussalam Medan.

\section{Saran}

Berdasarkan kesimpulan diatas, maka sebagai tindak lanjut penelitian ini perlu diungkapkan saran-saran sebagai berikut :

1. Guru bidang studi seni budaya hendaknya dapat menggunakan model pembelajaran yang efektif sesuai dengan materi pembelajaranyang disampaikan. Sehingga siswa tidak merasa bosan dan jenuh dalam mengikuti pelajaran.

2. kemampuan siswa dalam pembelajaran tari perlu ditingkatkan lagi dengan adanya penerapan pemanfaatan media audio visual.

3. Disarankan agar peneliti selanjutnya tetap memperhatikan perkembangan 
model-model pembelajaran yang digunakan disekolah khususnya dalam pembelajaran seni tari.
DAFTAR PUSTAKA

Ali, Mohamad, 2013:126, Penelitian Kependidikan (Prosedur \& Strategi), Bandung: Angkasa.

Arief S Sadirman, dkk, 2007, Media pendidikan, Jakarta: PT. Raja Grafindo Persada

Armah,, 2012, Jurnal, Pengaruh Media Audio Visual Terhadap Kemampuan Menulis Teks Berita Oleh Siswa Kelas VIII SMP PGRI Percut Sei Tuan, Medan.

Djahiri, Khosasih,1980:3, Menelusuri Dunia Afektif Pendidikan Nilai dan Moral, Bandung: Penerbit Lab Pengajaran PMP-KN.

Djuharie, O. Setiawan, 2001:52, Panduan Membuat Karya Tulis, Bandung: Yrama Widya.

Fachrunnisa, 2016, Skripsi, Penerapan Pembelajaran Tari Sitalasari Melalui Media Audio Visual Pada Siswa Sekolah Menengah Pertama (SMP) Bintang Langkat, Unimed.

Fitria Pane, Lailatul, 2016, Skripsi, Pembelajaran Tari (Tatak) Tintoa Serser Melalui Media Audio Visual Untuk Siswa Sma Swasta Daerah Sei Bejangkar, Unimed.

Hamalik, 2004:4, Berdasarkan Pendekatan Kompetens, Jakarta: PT. Bumi Aksara.

Miarso, 2004:528, Menyemai Benih Teknologi Pendidikan, Jakarta: Prenada Media.

Munadi, 2008:57, Media Pembelajaran Sebuah Pendekatan Baru, Jakarta: Gaung Persada.

Murti Lokasari,Novian, 2013, Skripsi,Proses Pembelajaran Seni 
Tari Pada Siswa Kelas VIII SMP

Dalam Mata Kuliah Tari

Pendidikan Di Fakultas Bahasa

Dan Seni Universitas Negeri

Semarang, Universitas Negeri

Semarang.

Purwanto, 2009:122, Evaluasi Hasil

Belajar, Yogyakarta: Pustaka

Pelajar.

Ramadana, Fitri, 2014, Skripsi, Pengaruh Penggunaan Media Pembelajaran Audio Visual Terhadap Hasil Belajar Pembuatan Hiasan Siswa Kelas XII SMK Negeri 10 Medan, Medan.

Sudjana, 2002:22, Penilaian Hasil Proses Belajar Mengajar, Bandung: Remaja Rosdakarya.

Supranto, 2004:27, Analisis Multivariat Arti dan Interpretasi, Jakarta: Rieka Cipta.

Sutikno, 2007:6, Menggagas Pelajaran Efektif dan Bermakna, Mataram: NTP Press

Usnita, 2013:18, Pengaruh Penggunaan Media Audio Visual Terhadap Hasil Belajar Biologi Pada Siswa SMA Kemala Bhayangkari,Medan, Universitas Sumatera Utara.

Usnita, 2013:25, Pengaruh Penggunaan Media Audio Visual Terhadap Hasil Belajar Biologi Pada Siswa SMA Kemala Bhayangkari,Medan, Universitas Sumatera Utara.

Yamin,2005:99, Strategi Pembelajaran Berbasis Kompetensi, Jakarta: Gaung Persada Press 